\title{
EL WEBDOC, UN FORMATO MULTIMODAL EN EL ENTORNO TELEVISIVO DIGITAL MULTIPANTALLA. EL CASO DE CROMOSOMA CINCO
}

\section{WEBDOC, A MULTIMODAL FORMAT INTO DIGITAL MULTISCREEN TELEVISION ENVIRONMENT. THE CASE OF CROMOSOMA CINCO}

\author{
Mónica BARRIENTOS-BUENO \\ Universidad de Sevilla \\ mbarrientos@us.es
}

\begin{abstract}
Resumen: El docuweb se ha convertido en un formato pujante, adaptado a las particulares características del Audiovisual 2.0 y el entorno multipantalla; este artículo propone un acercamiento al mismo desde este punto de vista con el análisis de un caso concreto: Cromosoma cinco, del Laboratorio de Experimentación de RTVE. Ello supondrá incidir en aspectos como la narrativa no lineal, la interacción, la navegación por los contenidos adicionales multimedia, entre otros.

Palabras clave: Documental Interactivo. Multimodalidad. Interactividad. Contenidos Adicionales. Cromosoma cinco. RTVE.

Abstract: Docuweb has turned into a thriving format, adapted to the special features of Audiovisual 2.0 and the multiscreen environment; this paper sets an approach to it from this point of view, with a specific analysis of a singular case: Cromosoma cinco, by Experimentation Laboratory of RTVE. This will affect areas such as non-linear narrative, interaction, navigation through additional multimedia content, among others.
\end{abstract}

Key Words: Interactive Documentary. Multimodality. Interactivity. Additional Features. Cromosoma cinco. RTVE. 


\section{INTRODUCCIÓN}

En los últimos años el audiovisual está viviendo las transformaciones de la llamada tercera revolución industrial, que ha conducido a un escenario multipantalla donde se multiplican los formatos de difusión de contenidos, los dispositivos y la convergencia con la web impulsa un nuevo paradigma creativo, el Audiovisual 2.0 (Aguilera y Martínez, 2010). La integración de tecnologías está modificando y enriqueciendo el conjunto del sistema; en el caso de la experiencia televisiva a través de Internet, "proporciona un valor añadido a la televisión tradicional y, por otra parte, se ha convertido en parte fundamental de la infraestructura de distribución de la televisión en la actualidad" (Barrientos, 2013:6). Ver la televisión ha cambiado de forma rotunda la industria que genera los contenidos, a estos mismos (nuevos formatos, específicamente creados para Internet, narrativas no lineales, transmedia y crossmedia, hibridación de información y entretenimiento), así como los procesos de comunicación, a lo que hay que añadir que la distribución y recepción de los mensajes "ya no descansa necesariamente en la recepción sincrónica de unos contenidos organizados en un flujo continuo" (Aguilera, 2009: 9).

En el escenario de convergencia de pantallas, el smartphone se asienta en el consumo de contenidos audiovisuales con un $54 \%$, del que un $14 \%$ son usuarios que afirman ver vídeos de más de treinta minutos en su móvil gracias a la extensión de la red 4G; su pujanza en el entorno del consumo televisivo se debe a la inmediatez del acceso frente a otros dispositivos y su acompañamiento continuo del usuario (Televidente 2.0, 2015). El multitasking o multitarea es ya una práctica común: el $60 \%$ de los usuarios utilizan habitualmente otros dispositivos mientras ven televisión.

El resultado actual de este panorama es la adaptación de las cadenas de televisión, ofreciendo un amplio mapa de servicios (desde contenidos extra a visionados a la carta) con el que mejoran las relaciones con sus espectadores. En definitiva, "esta nueva enhanced televisión cambia la percepción del espectador, fortalece sus relaciones con la cadena y le 'engancha' aún más con el contenido" (Bowling y Chan-Olmsteed, 2001: 204). Internet se convierte así en la plataforma de muchos de los servicios que reciben los espectadores.

El Audiovisual 2.0 ha abierto las puertas a uno de los aspectos más codiciados por el audiovisual durante décadas: la posibilidad de una interactividad real con el espectador y la implantación de nuevos modelos de negocio. El espectador multipantalla y, especialmente el nativo digital, demanda, además de interacción, servicios y contenidos adicionales a los que ofrece tradicionalmente el visionado de producciones audiovisuales. En esta línea podemos situar la contribución del documental multimedia interactivo, un desarrollo adaptado del documental a las circunstancias del Audiovisual 2.0 que suma 
diferentes recursos adicionales (vídeos, enlaces web, fotografías, etc.) con el propósito de enriquecer el contenido y la experiencia del espectador.

Las páginas que siguen estudian el docuweb como formato al abrigo del Audiovisual 2.0, tomando como análisis particular de caso el documental web Cromosoma cinco (2013), del Laboratorio de Innovación Audiovisual de RTVE.

\section{WEBDOC, UNA APROXIMACIÓN}

En el entorno audiovisual multipantalla encontramos el webdoc en el punto de intersección entre el documental y lo digital, un formato concebido para su distribución y consumo en Internet. Sus características surgen precisamente de la fusión, donde "el género documental aporta sus variadas modalidades de representación de la realidad, y el medio digital, las modalidades de navegación" (Gifreu, 2014). Webdoces tan solo una de las muchas denominaciones empleadas para identificar este nuevo formato emergente en el ámbito del documental interactivo, consolidado este como uno de los imprescindibles de la no ficción interactiva. También es conocido como documental web, web documental o docuweb, apelando así a su forma de distribución y algunas de sus características. Otras denominaciones, como documental transmedia, inciden en aspectos como el empleo de la web para expandir la narración y enriquecer el contenido, la interactividad de la audiencia y la participación de las aplicaciones y dispositivos móviles para acercar la experiencia transmedia (Scolari, 2013). Al margen de la designación, su esencia radica en ser una producción multimedia, con orientación netamente interactiva y heterogénea en cuanto a recursos empleados, pensado para su distribución a través de la red. Como apunta Gifreu, es un nuevo escenario el que ha propiciado la producción de "obras de frontera que integran una combinación de lenguajes y sistemas de comunicación (multimodalidad), junto con nuevas experiencias interactivas donde los usuarios adquieren un papel fundamental" (2013: 30).

Narrativamente, el webdoc plantea la no linealidad al espectador, de manera que él mismo pueda trazar su propia ruta a través de un esqueleto hipertextual compuesto por nodos, vínculos y anclas (Gifreu, 2014), saltando de un recurso a otro, interrumpiendo el visionado del documental para ampliar determinado aspecto a través del contenido sugeridoy, posteriormente, continuar con él si lo desea. Se crean así categorías discursivas temáticas que "generan un tipo de interpretación descriptiva enriquecida, no solo por su mayor amplitud y profundidad, sino también por las vinculaciones coherentes que se establecen con las restantes" (Gifreu, 2014). El tradicional espectador pasivo se convierte así en prosumidor del documental interactivo: lo consume y lo crea a la vez a través el trazado que elige para la navegación entre los elementos multimedia, por lo que adopta el rol de co-editor, además de interactuar en tiempo real, llegando incluso a ir más allá de 
la interpretación y alcanzar la argumentación con el volcado de sus opiniones en blogs, redes sociales y foros a los que se enlaza. Ello refleja cómo "el hipertexto hace visible su propia condición discursiva a través de elementos que no están organizados según un orden lógico ni responden a una guía establecida de lectura, restringiendo el acto enunciativo a la interacción del usuario, desencadenante de la generación de sentido" (Arnau, 2013:5). De esta manera, y acogiéndonos a la clasificación realizada por Berenguer y sistematizada por Gifreu (2014), el webdoc como documental interactivo muestra una interacción multimedia por las diferentes modalidades de navegación e interacción.

El fin del webdoc es esencialmente informativo y, a partir de ello, expandir la experiencia del espectador y llevarle a terrenos de interés personal por el tema tratado. Por su narrativa no lineal se trata de una forma de comunicar muy cercana a la mecánica lúdica del videojuego, ya que el espectador juega con las posibilidades que el webdoc le ofrece, safisfaciendo así su primera necesidad: la diversión y el entretenimiento a través de historias contadas mediante la combinación de diferentes medios, utilizando las herramientas y funciones específicas de la web; a lo que se suma un segundo nivel en el cual, mediante la gamificación, se logra una completa inmersión del seguidor.

La interactividad viene dada por la navegación por contenidos adicionales multimedia que ofrece el formato, los cuales aparecen de acuerdo a un timeline regido por el desarrollo lineal del documental a partir del cual, con las sugerencias realizadas, el espectador puede saltar de la producción principal a vídeos, fotografías, enlaces web, audios, etc. que tienen que ver con su interés en el tema y, además, personalmente en su propósito de profundizar en las cuestiones y vías planteadas por el documental. De hecho se trata de una de sus principales características: el receptor-usuario "adopta un nuevo papel activo en relación al papel pasivo que hasta ahora ha venido desempeñando, fundamentalmente dentro de un entramado de estructuras para narrar una determinada realidad" (Rodríguez y Molpeceres, 2013: 250). Por lo que, sin duda, el éxito de un diseño webdoc implica ir más allá de la mera información y promover la curiosidad, la cual puede ser colmada de diferentes maneras según los intereses personales del espectador. Como apunta Gifreu (2011), mediante la participación interactiva los usuarios pueden tener una experiencia única, aportando opciones y cierto control sobre el documental e interactuando con la historia que se les está contando, eligiendo qué quiere ver y en qué orden. Desde el punto de vista narrativo, el orden de acceso a los contenidos adicionales no altera o desvirtúa el sentido final y el punto de vista que los autores han querido dar a su producción, sino que lo complementa y amplía a través de los recursos propuestos para representar la realidad. Por otra parte, el documental web también depende de un soporte técnico donde diseño y programación, muy cercanas al videojuego, tienen un papel decisivo para crear producciones atractivas. 
De esta manera, las características del webdoc pueden resumirse visualmente con este gráfico:

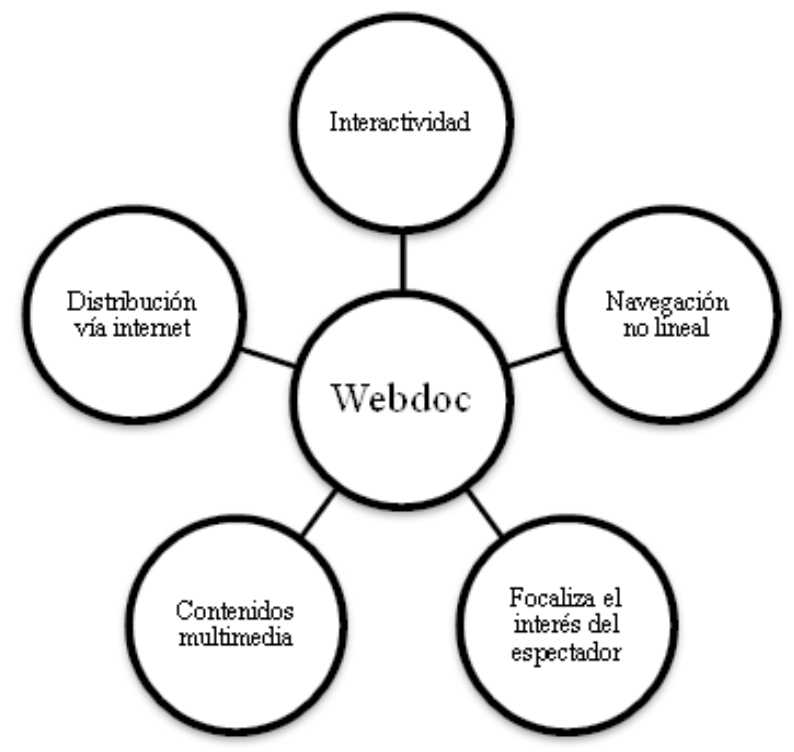

Figura 1. Características del webdoc (elaboración propia)

El documental multimedia, contenedor en el que se integra el documental web, se perfila como un formato en constante evolución que actualmente experimenta "un período de transición de las formas tradicionales del documental hacia las nuevas formas de expresión, de circulación y de intervención propias del medio digital" (Gifreu y Moreno, 2014: 44). Vive una hibridación a la que no son ajenas otras expresiones y formas audiovisuales.

La historia del docuweb en España se remonta a 2007, cuando el equipo de 30 minuts de TV3 realizó un documental sobre el Guernica de Picasso, Guernica: pintura de guerra, que iba complementado con un proyecto transmedia que fomentaba la interactividad (Scolari, 2013: 207-208). Desde entonces, el fenómeno del webdoc no ha hecho más que crecer, tanto en el ámbito académico con postgrados especializados como proyectos específicos para su fomento y desarrollo (como la conferencia y exposición InterDocs Barcelona, 2013). Industrialmente conviven proyectos de bajo presupuesto, llevados a cabo por pequeñas productoras y grupos de trabajo, con otros de mayor envergadura gracias al apoyo de televisiones públicas. En el ámbito estrictamente español, Televisió de Catalunya ha trabajado con el formato (Les veus d'una generació) y a ello se ha sumado el Laboratorio de Experimentación Audiovisual de Radio Televisión Española, con varios webdocs en línea, entre los que se encuentra Cromosoma cinco. 


\section{CROMOSOMA CINCO, UN WEBDOC DEL LABORATORIO DE EXPERIMENTACIÓN DE RTVE}

Radio Televisión Española ha sido uno de los primeros operadores en España que ha incluido servicios innovadores en su portal web (Vinader y Abuín, 2010), muchos de ellos desarrollados por el Laboratorio de Experimentación de la corporación, un grupo de cinco profesionales, comandados por Ismael Recio, que se define como "un departamento de innovación audiovisual que ofrece enfoques creativos que nunca dejan indiferente" ${ }^{\prime \prime}$. Han desarrollado webdocs, navegaciones interactivas (dedicadas, por ejemplo, a los entresijos del cónclave vaticano para la elección de Papa, para conocer personajes y datos históricos relacionados con las tramas de la serie Isabel e incluso algunos lúdicos como la elección de la invitada mejor vestida de la gala de entrega de los Goya), timelines o cronologías relacionadas con diferentes hechos (la historia de las videoconsolas y los diez años de Cuéntame cómo pasó, por ejemplo), atractivos gráficos con datos de actualidad en la sección 'periodismo de datos', entre otros desarrollos. Todos ellos están marcados por un gran cuidado tanto de los contenidos como del aspecto visual, con especial incidencia en la relevancia dada al diseño.

Cromosoma cinco fue emitido por TVE-2 el 24 de abril de 2013², estando desde entonces disponible en el portal de RTVE con la opción de visionado como docuweb, con sus contenidos extra adicionales. Al acceder al enlace, ya se invita al espectador a visionarlo en el formato interactivo con un banner emergente a la izquierda, tal como se muestra en la figura siguiente:

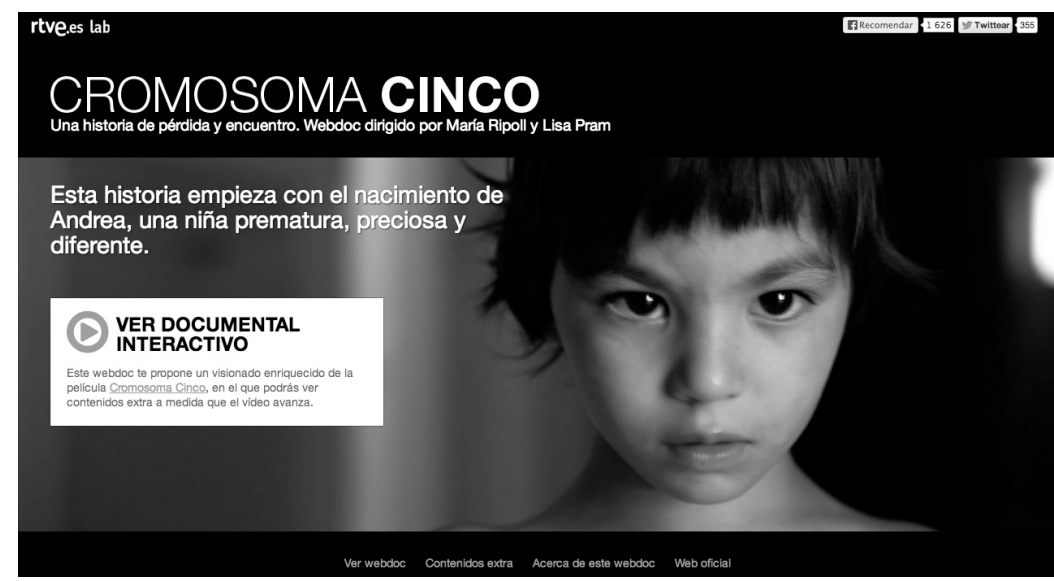

Figura 2. Distribución de elementos en la interfaz durante la reproducción del webdoc

1 Laboratorio de Experimentación Audiovisual de RTVE. Quiénes somos. http://lab.rtve.es/quienessomos. html.

2 http://www.rtve.es/rtve/20130422/tve-estrena-cromosoma-cinco-2-cineteca-dentro-del-ciclo-somosdocumental/646321.shtml. 
Las directoras y guionistas del proyecto, María Ripoll y Lisa Pram (esta última madre de Andrea, la niña protagonista), señalan algunas de las claves del formato: llegar a la mayor parte de público posible para promover el conocimiento de una realidad social como es el síndrome que padece Andrea, bajo un manto de intimismo y divulgación que busca ante todo la sensibilización. Además, ellas mismas apuntan que "la capacidad multimedia e interactiva además proporciona a la historia la posibilidad de crear una exposición no lineal del argumento. Éste es un proyecto multidisciplinar, que combina varios formatos [...] para profundizar en la información que se desprende de la película. Con el webdoc ofrecemos la máxima información al espectador y somos capaces de divulgar todos los aspectos posibles de nuestra historia"3.

El webdoc se estructura en nueve capítulos, visualmente organizados en un timeline que acompaña al visionado del documental, sobre la barra de reproducción, y cuyas invitaciones a ampliar información y contenidos son banners emergentes a izquierda y derecha (tal como se muestra en la figura 3), los cuales funcionan no solo como primera vía de acceso al contenido multimedia adicional, sino también como estímulos visuales y reclamos. De esta manera estamos ante una modalidad de navegación partida, al poder circular por la línea de capítulos representada sobre la barra de reproducción, "metáfora gráfica de la secuencia ordenada de los principales ejes temáticos" (Gifreu, 2014), que se combina con las modalidades de navegación a través de contenidos audiovisuales y navegación hipertextual para los elementos adicionales emergentes sugeridos.

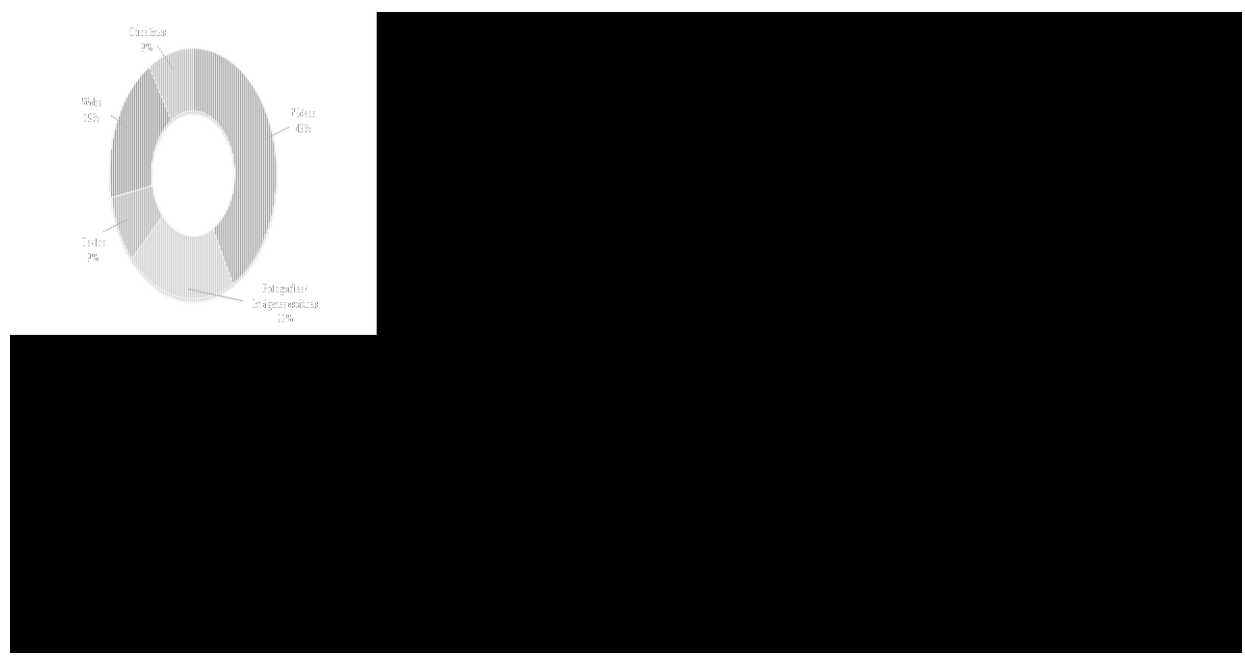

Figura 3. Distribución de elementos en la interfaz durante la reproducción del webdoc

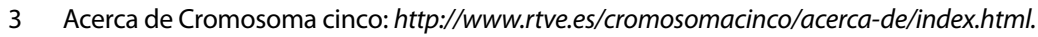


El documental parte de las circunstancias que rodearon al nacimiento de Andrea (capítulo 1), para después mostrar en primera persona el largo camino seguido por sus padres para encontrar respuestas sobre lo que le sucedía a la pequeña Andrea (capítulo 2). Finalmente consiguen un diagnóstico (capítulo 3) que permite describir y acercar al espectador al síndrome relacionado con una mutación del cromosoma cinco (capítulo 4). A todo ello no es ajeno el dolor (capítulo 5), mientras a la vida de Andrea y sus padres llega Billie, hermana de la protagonista (capítulo 6). Andrea trabaja y lucha por comunicarse, encontrando gracias a sus profesoras un camino para ello (capítulo 7); el documental cierra con algunos aspectos que hacen a la joven protagonista alguien muy especial (capítulo 8), incluido su entorno familiar (capítulo 9). Permite el acceso no lineal a la narrativa fragmentada del webdoc, de manera que el usuario puede elegir de forma selectiva el capítulo que desea ver, así como navegar por la misma según la ruta que desee a partir de las elecciones que haga; de esta manera se presentan dos espacios diferenciados de interacción: "el 'espacio de representación' que es aquel donde se desarrollan los contenidos que se seleccionan en la interfaz y el 'espacio de selección', que hace referencia a la interfaz" (Rodríguez y Molpeceres, 2013: 256). En consecuencia, la organización del discurso narrativo recae en el usuario. Por otra parte, y en relación con el grado de interactividad, estaríamos ante un caso semicerrada bajo los términos que define Gaudenzi (2012), pues permite la participación del usuario a través de la navegación pero no el cambio del contenido.

Los elementos multimedia adicionales, que constituyen la esencia del webdoc, son cincuenta y siete; atendiendo a su naturaleza y contenido, se pueden clasificar en vídeos, fotografías e imágenes estáticas, textos, enlaces a páginas web de interés social relacionadas con el tema del Síndrome de Maullido de Gato y otros links. Porcentualmente se distribuyen así, tal como se muestra en el siguiente gráfico: 


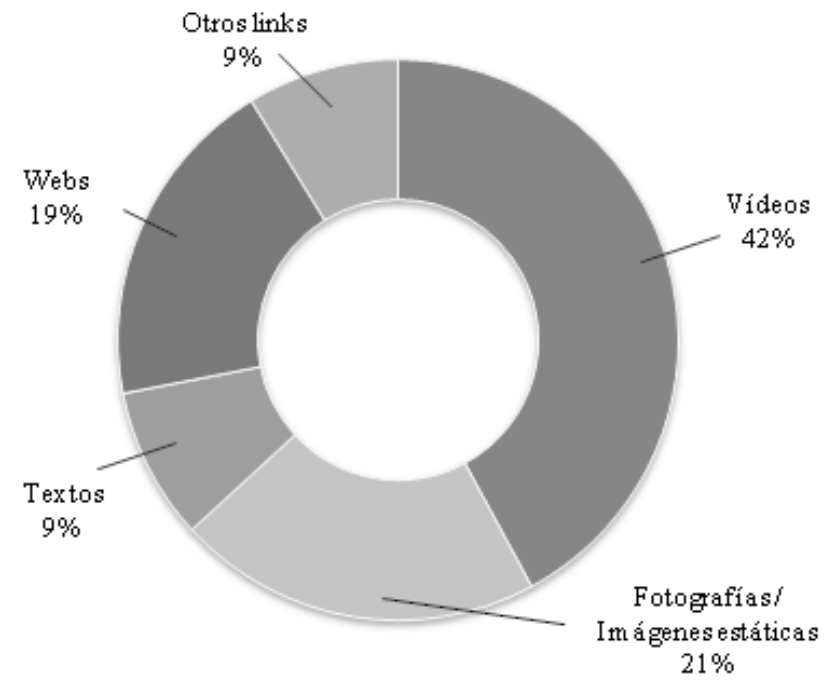

Figura 4. Distribución de los contenidos adicionales según su naturaleza (elaboración propia)

El conjunto de recursos videográficos reúne tanto entrevistas propias, realizadas para Cromosoma cinco, de las cuales en el documental aparecen tan solo algunos totales, como enlaces a vídeos externos alojados en repositorios (YouTube) y páginas web (Ted Talks). Entre las entrevistas, todas ellas completas, y en ocasiones ofrecidas en dos partes, se encuentran la de genetista que diagnosticó a Andrea, su fisioterapeuta, su logopeda, un psiquiatra y varias profesoras de educación especial. A través de todas ellas nos acercamos, de una manera muy directa al día a día y los problemas inherentes al síndrome de Andrea, los cuales son extrapolables a cualquier otra persona afectada por la misma alteración genética, ayudando al espectador a adentrarse en el tema desde una multiperspectiva profesional y personal a la vez. También se suman vídeos divulgativos procedentes de otras fuentes, para ello se recurre a enlazar a YouTube con audiovisuales como el informativo sobre el síndrome Cri du chat de la Fundación Síndrome 5p y otros más personalizados, de casos concretos, como el de Rocío y Bárbara, también afectadas por el síndrome. El cazo de Lorenzo (Isabel Carrier) es un montaje audiovisual del libro homónimo que pretende sensibilizar sobre la discapacidad infantil e In my language (A. M. Braggs), donde la especial forma de comunicarse de su protagonista autista con el mundo sirve para cuestionar nuestras fórmulas de comunicación.

Otra serie de recursos videográficos, con propósito igualmente educativo y divulgativo, proceden de los respectivos links que se realizan a la página Ted Talk, todos ellos relacionados con experiencias directas que relatan la pérdida de capacidad cerebral 
debida a diferentes causas, desde The powerful stroke of insight, donde la investigadora científica Jill Bolte Taylor explica cómo experimentó la pérdida funcional de su cerebro debido a un accidente cerebrovascular y The world needs all kinds of minds, donde Temple Gradin, autista, explica cómo funciona su mente, hasta Pain perception and the human brain, relativo a la percepción del dolor por parte del cerebro, pasando por propuestas sobre la educación de personas con necesidades especiales con School kills creativity y Changing education paradigms. Véase la figura 5, donde se agrupan varios de ellos:

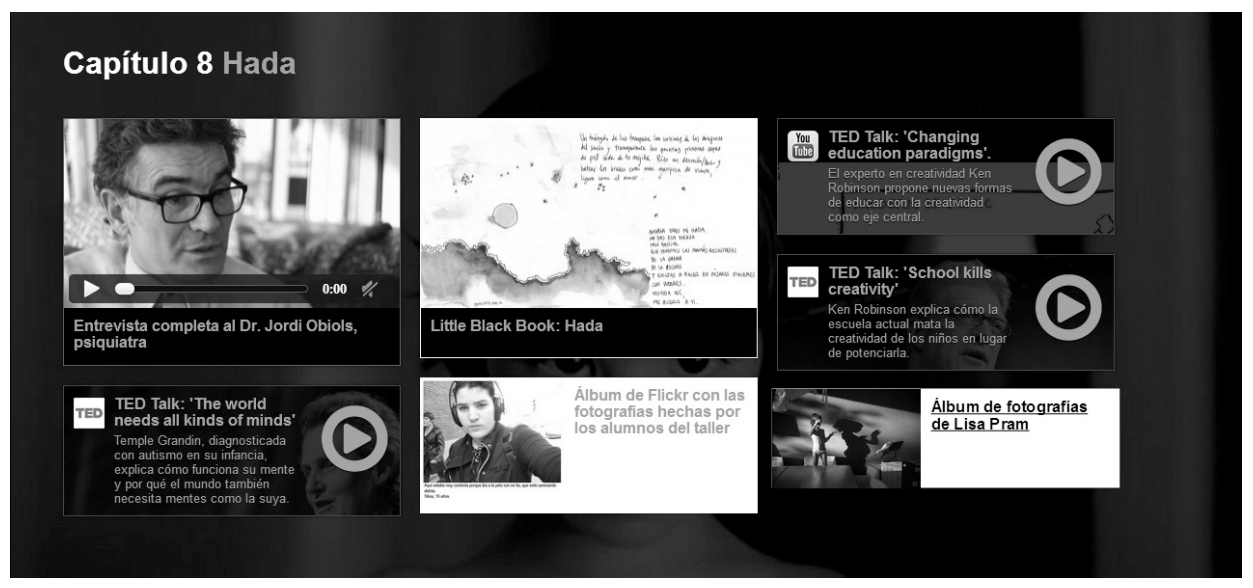

Figura 5. Contenidos adicionales del capítulo 8 con predominio de los de naturaleza videográfica

Varios de los contenidos adicionales videográficos son obras de creación, concretamente se enlaza, a través de YouTube, a trailers de películas que se acercan a historias de personas aquejadas de diferentes enfermedades y síndromes, como The horse boy (Michael Onion Scott, 2009) y el viaje de su protagonista autista, Mary \& Max (Adam Elliot, 2009) y la relación entre una niña y un autista, La escafandra y la mariposa (Julian Schnabel, 2007), donde la historia de superación de su protagonista inspiró a las directoras para hacer Cromosoma cinco. Se suman los trailers de María y yo (Félix Fernández de Castro, 2010), documental sobre el día a día de una persona autista y Yo, también (Antonio Naharro y Álvaro Pastor, 2009), film que nos acerca a la historia del primer europeo con Síndrome de Down que consigue un título universitario. Con ello se invita al espectador a conocer producciones cinematográficas que abordan estos temas y, también, a visionarlas para conocer otras aristas.

Cromosoma cinco, entre sus contenidos adicionales, también cuenta con enlaces que permiten el visionado completo de cortometrajes, que, como el resto de materiales del webdoc, nos invitan a conocer de forma más profunda del síndrome que sufre Andrea. Se vuelve a recurrir a enlaces a YouTube que llevan al espectador a Mon petit frère de 
la lune (Fred Philibert, 2010), cortometraje de animación focalizado en una niña de seis años que explica los síntomas del autismo de su hermano y El curioso incidente del perro a medianoche (Mark Haddon, 2003), cortometraje que nos aproxima al Síndrome de Asperger.

El documental abre y cierra con un recurso fotográfico, el Little Black Book, que nos guía a través de todo su desarrollo por la vivencia personal de Lisa Pram; en realidad, se trata del diario que ella misma realizó donde conviven textos, fotografías y dibujos que dedica a sus hijas (véase figura 6). De hecho, sobre la ventana de visualización de Cromosoma cinco hay un enlace a Little Black Book, descrito como "el diario personal que empieza a escribir Lisa Pram durante un periodo de gran incertidumbre [...], una pieza íntima"4, en la que se basa este documental, de ahí su protagonismo entre los contenidos adicionales. Además se emplea como vehículo de navegación hacia los distintos capítulos.
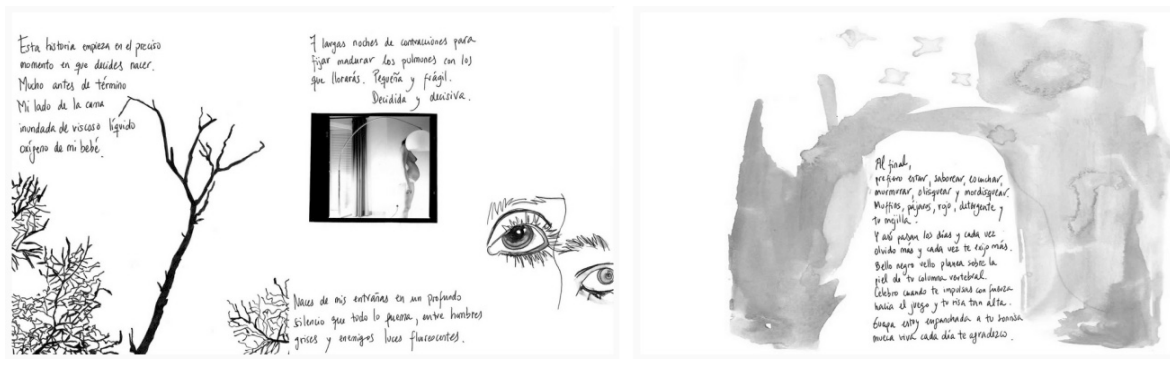

Figura 6. Little Black Book: naces [capítulo 1] (izquierda) y luz [capítulo 9] (derecha)

Los contenidos adicionales fotográficos se completan con una imagen de Google Maps que muestra la distancia entre Cataluña, Dinamarca y Laponia cuando, uno de los facultativos médicos, sugirió la ascendencia lapona de la madre de Andrea, danesa, a tenor de los rasgos faciales de la niña y varios enlaces a álbumes en Flickr compuestos por imágenes de la propia Lisa Pram y por alumnos del taller Fasia.

Los enlaces web a páginas de fundaciones, asociaciones y colegios promueven ante todo la información; de esta manera se incluyen links a la Asociación de Padres de Niños Prematuros, Fundación Síncrome 5p, Asociación Nacional de Afectados por el Síndrome de Maullido de Gato, Federación Española de Enfermedades Raras y varios directorios de Centros de Salud Mental en Barcelona y Madrid, entre otros.

Otros enlaces conducen al espectador, convertido en esos momentos en navegante y lector, a textos de noticias y reportajes de los diarios La Vanguardia y El País y la página de la Organización Mundial de la Salud, centrados especialmente en los nacimientos de bebés prematuros, a los que se suma también la entrada del Síndrome de Maullido

4 Cromosoma cinco. Índice: http://www.rtve.es/cromosomacinco/ver/index.html. 
de Gato en la Wikipedia. Por su carácter más explicativo, se concentran en los cuatro primeros capítulos del docuweb, presentándose el último en el siete: una entrevista a Lary León en La Vanguardia, nacida sin brazos y una pierna.

Finalmente tenemos una serie de otros recursos como son el link a la web de Lisa Pram, directora y guionista de Cromosoma cinco y también madre de Andrea, como ya hemos mencionado, a lo que se suman varios enlaces a Amazon de libros de fotografías: Family (Lee Friendlander), Inmediate Family (Sally Mann) y Revelations (Diane Airbus), todos ellos con un hilo conductor: la familia y lo cotidiano. Todos ellos se encuentran entre los contenidos adicionales del capítulo 6, dedicado a la hermana de Andrea, Billie. El último vínculo es a la ficha del libro El curioso incidente del perro de medianoche (Mark Haddon) en FNAC.

La reorganización narrativa aparece así conectada con el modo en el que se presenta el discurso, especialmente por la presentación de recursos multimedia e hipermedia que expanden el texto y multiplican los puntos de vista implicados en la realidad de la enfermedad de Andrea, la experiencia del usuario y la ampliación de información.

\section{A MODO DE CONCLUSIÓN}

El actual entorno de convergencia y multipantalla favorece la aparición de formatos que se adaptan a las nuevas formas de distribución y visionado, marcados esencialmente por Internet. Varias de las claves son la interacción, el acceso a contenidos adicionales y las rutas no lineales: a ello se adapta el webdoc o documental web. El webdoc es un formato de documental que está teniendo una creciente implantación en el mercado español y que, en el caso de RTVE, está siendo desarrollado por el Laboratorio de Experimentación, donde se trabaja con otras fórmulas innovadoras donde la interacción y la navegación por los contenidos es la clave.

Cromosoma cinco emerge asícomo un webdoc que cumple con todas las características

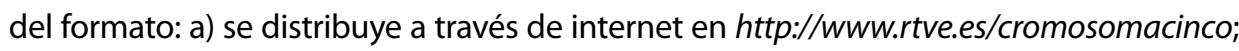
b) la navegación es no lineal, ya que permite saltar entre sus nueve capítulos así como entre sus contenidos adicionales sugeridos, aunque el webdoc propone una ruta con su organización en capítulos; c) focaliza el interés del espectador, ya que él mismo puede construir su experiencia con el documental, trazando su propia ruta de vídeos, fotografías, textos y enlaces visitados; d) contiene una amplia tipología de contenidos multimedia, con predominio de vídeos, varios de ellos entrevistas íntegras realizadas para el documental y otros como trailers de largometrajes, cortometrajes, producciones divulgativos, entre otros. A ellos se suman fotografías, especialmente el Little Black Book, el diario escrito por Lisa Pram que inspiró Cromosoma Cinco. Los links a asociaciones, fundaciones y colegios tienen una función esencialmente informativa, completada por 
EL WEBDOC, UN FORMATO MULTIMODAL EN EL ENTORNO TELEVISIVO DIGITAL MULTIPANTALLA. EL CASO DE CROMOSOMA CINCO

los vínculos a noticias textuales; e) y todo lo comentado redunda en la interactividad del espectador que, con la estructura de navegación del webdoc y su atractivo en cuando a diseño visual, lleva implícito el elemento lúdico.

\section{REFERENCIAS BIBLIOGRÁFICAS}

AGUILERA MOYANO, M. de (2009).“Innovación, prácticas culturales y contenidos audiovisuales. Una introducción". En Una tele en el bolsillo. La televisión en el teléfono móvil: contenidos, formatos, audiencias, M. de Aguilera Moyano y M. Meere, (eds.), 9-16. Málaga: Círculo de Estudios Visuales Ad Hoc.

AGUILERA MOYANO, M. de y MARTíNEZ GARCÍA, M. A. (2010). “La TV en transición (Usuarios y prácticas culturales en el marco del Audiovisual 2.0.). En Contenidos Audiovisuales 2.0. VIII Jornadas Profesionales, 25-39. Fundación Audiovisual de Andalucía.

ARNAU ROSELLÓ, R. (2013). “La representación hipertextual de la realidad: nociones para un estudio analítico del webdocumental contemporáneo". En Actas del V Congreso Internacional Latina de Comunicación Social. La Laguna: Universidad de La Laguna: http:// www.revistalatinacs.org/13SLCS/2013_actas/195_Arnau.pdf [31/05/2015].

BARRIENTOS-BUENO, M. (2013). "La convergencia y la segunda pantalla televisivas: el caso de Isabel (TVE)". En Actas del I Congreso Internacional Comunicación y Sociedad. Logroño: Universidad Internacional de la Rioja: http://reunir.unir.net/bitstream/ handle/123456789/1731/BARRIENTOS\%20BUENO\%20M\%C3\%93NICA.pdf?sequence $=3$ [13/07/2015].

BOWLING, L. \& CHAN-OLSMTED, M. (2001). "Enhanced TV as brand extension: TV viewers' perception of enhanced TV features and TV commerce on broadcast networks' web sites". The International Journal on Media Management3 (IV), 202-212: http://www. mediajournal.org/ojs/index.php/jmm/article/viewFile/187/71 [30/05/2015].

GAUDENZI, S. (2012). The Living Documentary: from representing reality to co-creating reality in digital interactive documentary. London: University of Goldsmiths (Tesis doctoral): http:// research.gold.ac.uk/7997/1/Cultural_thesis_Gaudenzi.pdf [31/07/2015].

GIFREU CASTELLS, A. (2011). “El documental multimedia interactivo como discurso de la no ficción interactiva. Por una propuesta de definición y categorización del nuevo género emergente". Hipertext.net 9: http://www.upf.edu/hipertextnet/numero-9/documentalmultimedia.html [02/06/2015].

(2013). "El documental interactivo: estado de desarrollo actual". Obra Digital 4 (1), 29-55. (2014). El documental interactivo. Evolución, caracterización y perspectiva de desarrollo. Barcelona: Editorial UOC. 
GIFREU CASTELLS, A. y MORENO, V. (2014). "Estrategias y modelos de financiación del documental interactivo y transmedia". Fonseca, Journal of Communication 9, 41-63: http:// revistas.usal.es/index.php/2172-9077/article/view/12241/12591 [15/05/2015].

RODRÍGUEZ FIDALGO, M. I. y MOLPECERES ARNÁIZ, S. (2013). "Los nuevos documentales multimedia interactivos: construcción discursiva de la realidad orientada al receptor activo". Historia y Comunicación Social 18 (especial diciembre), 249-262: http://dx.doi.org/10.5209/ rev_HICS.2013.v18.44325 [31/05/2015].

SCOLARI, C. A. (2013). Narrativas transmedia. Cuando todos los medios cuentan. Barcelona: Deusto.

THE COCKTAIL ANALYSIS (2015). Informe ejecutivo Televidente 2.02014 (VIII Oledada), febrero: http://www.slideshare.net/TCAnalysis/el-54-de-los-usuarios-de-smartphone-utilizan-estedispositivo-para-ver-contenidos-audiovisuales [03/06/2015].

VINADER SEGURA, R. y ABUÍN VENCES, N. (2010). “Las estrategias digitales de los operadores de televisión: nuevos modelos e interacción en la era digital". En Actas de Il Congreso Internacional Latina de Comunicación Social. La Laguna: Universidad de La Laguna: http:// www.revistalatinacs.org/10SLCS/actas_2010/40Abuin333.pdf [01/06/2015]. 

